\title{
TRAPEZIUS TRANSFER IN TRAUMATIC BRACHIAL PLEXUS PALSY
}

\author{
R. Ashik Ahamed ${ }^{1}$, V. Ramadevi ${ }^{2}$
}

${ }^{1}$ Resident, Department of Plastic Surgery, Government Stanley Medical College, Chennai.

2 Professor and HOD, Department of Plastic Surgery, Government Stanley Medical College, Chennai.

\section{ABSTRACT}

\section{BACKGROUND}

Traumatic brachial plexus injuries can cause total or partial loss of function of the upper limb. The loss of functional movements in the shoulder impairs the function of the entire upper limb even if there is functional movement in other joints like the elbow, wrist, and fingers. Various procedures like tendon transfers, neurotisation or arthrodesis are available to improve the function of the shoulder.

The aim of this study is to evaluate the results of the trapezius transfer for reconstruction of shoulder motion in adult patients with longstanding traumatic brachial plexus injuries.

\section{MATERIALS AND METHODS}

This study was done in a tertiary care institution and included 42 traumatic brachial plexus injury patients who underwent trapezius transfer for restoration of shoulder abduction and forward flexion during a period of eighteen months from August 2014 to July 2016. All patients underwent a modified Bateman, Saha method. Those who had inadequate or incomplete records and those who were not on regular follow-up were excluded from our study. The records of these patients were reviewed in March 2017 and the shoulder function and stability were re-evaluated clinically and results tabulated.

\section{RESULTS}

The shoulder function was improved in 35 patients. The average gain in shoulder abduction was $40.68^{\circ}\left(\right.$ Range $0^{\circ}$ to $\left.90^{\circ}\right)$ and the average gain in shoulder forward flexion was $35.36^{\circ}$ (Range $10^{\circ}$ to $75^{\circ}$ ). $92.86 \%$ of the patients had their inferior subluxation of the humerus corrected radiographically. The average gain in postoperative range of motion was similar to those achieved in other large series studies.

\section{CONCLUSION}

The transfer of trapezius is a simple procedure which can restore the abduction and forward flexion of shoulder in majority of the patients.

\section{KEYWORDS}

Trapezius Transfer, Brachial Plexus Injury, Reconstruction.

HOW TO CITE THIS ARTICLE: Ahamed RA, Ramadevi V. Trapezius transfer in traumatic brachial plexus palsy. J. Evolution Med. Dent. Sci. 2017;6(39):3163-3167, DOI: 10.14260/Jemds/2017/683

\section{BACKGROUND}

In patients with brachial plexus injury, the persistent instability of the shoulder and the lack of movements in shoulder joint significantly hinder the use of upper limb even if the function of elbow, wrist, and fingers is normal. Recovery of the function of deltoid and rotator cuff muscles is often incomplete and this results in a poor abduction and limited or no external rotation of the shoulder. When abduction and external rotation of the shoulder joint is limited, the upper limb cannot be positioned in front of the body in a coronal plane and this limits the functional use of the affected limb.

When the time since the injury is less than one year the shoulder abduction and external rotation are reconstructed by means of neurotisation and nerve transference with nerve anastomosis. When these neurosurgical procedures fail or when the time since the injury is more than one year,

Financial or Other, Competing Interest: None.

Submission 10-04-2017, Peer Review 04-05-2017,

Acceptance 10-05-2017, Published 15-05-2017.

Corresponding Author:

Dr. R. Ashik Ahamed,

Department of Plastic Surgery,

Government Stanley Medical College,

Chennai - 600001

E-mail: dr.ashikahamed@gmail.com

DOI: $10.14260 /$ jemds $/ 2017 / 683$ secondary reconstruction is required to restore the varying degree of function to the paralysed shoulder joint. The secondary reconstruction procedures to improve the function and stability include shoulder arthrodesis, rotational osteotomy of the humerus and tendon-muscular transfers or a combination of these techniques.

Shoulder arthrodesis is preferred by many authors., $1,2,3,4$ Arthrodesis is irreversible, relies on scapulothoracic motion and permits only a limited range of abduction and includes a high incidence of complications, e.g., fractures ${ }^{1,2}$ and pseudoarthrosis. ${ }^{1,4}$ This procedure cannot be done in patients with limited scapulothoracic motion or paralysis of the periscapular muscles. Saha ${ }^{5}$ and Goldner 6 both recommended tendon transfer for a paralytic shoulder and used shoulder fusion only as a last resort.

Several muscle transfers have been tried to improve the stability and movement of the paralysed shoulder. These include the transfer of the trapezius, pectoralis major and teres major, latissimus dorsi, combined biceps and triceps, gracilis, and combined muscle transfers. Most were initially described for treatment of paralysis after poliomyelitis.7,8,5 In recent years, some authors have reported their good experience with trapezius muscle transfer for the paralytic shoulder after brachial plexus injuries. ${ }^{9,10}$ 
In this study, we evaluated the results of the trapezius transfer for reconstruction of shoulder motion in adult patients with longstanding traumatic brachial plexus injuries.

\section{MATERIALS AND METHODS}

In this observational study (case series), over a period of two years from August 2014 to July 2016, 41 male patients and 1 female patient with longstanding brachial plexus palsy underwent secondary reconstruction of the shoulder by transfer of trapezius muscle to proximal humerus. Those who had inadequate or incomplete records and those who were not on regular follow-up were excluded from our study. The records of these patients were reviewed in March 2017 and the shoulder function and stability were re-evaluated clinically. Modification of Bateman, ${ }^{11}$ Saha ${ }^{5}$ method was used for transfer of trapezius to the proximal humerus in all patients. In 9 patients, C5, C6 roots; in 12 patients, C5, C6 \& $\mathrm{C} 7$ roots and in the rest all the roots of the brachial plexus were injured. 28 patients had a right-sided injury and the rest had a left-sided injury. In 37 of these patients, the injury was due to road traffic accident and 23 had undergone treatment for associated head injury and fractures. Of these patients 17 had a previous failed neurosurgical procedure for reconstruction of the shoulder function.

The average age was 29.9 years (Range 20 to 47 ) and the average followup period was 14 months (Range 8 to 32). The average delay between the injury and the trapezius transfer procedure was 25.6 months (Range 9 months to 5 years 4 months).

In all patients, the strength of the trapezius muscle preoperatively was 4 and above as per MRC grading. The active abduction and forward flexion of shoulder movement was recorded (Angle between the arm and the upper trunk using goniometer). The mean of the preoperative maximum active shoulder abduction and forward flexion are calculated. If $20^{\circ}$ or more of active shoulder abduction of the shoulder is achieved, then the shoulder function is considered to have improved. The percentage of patients in whom the shoulder function is improved is calculated. The results were tabulated. The average preoperative shoulder abduction was $10.68^{\circ}$ (Range $0^{\circ}$ to $20^{\circ}$ ) and the average preoperative flexion was $15.59^{\circ}$ (Range $0^{\circ}$ to $30^{\circ}$ ). Passive range of abduction of shoulder joint was more than $80^{\circ}$ in all the patients. Clinical multidirectional instability and radiological inferior subluxation of the shoulder was present in all patients. Radiographically, there was no fracture of the humerus or scapula.

\section{Surgical Technique and Post-Operative Treatment}

The surgical procedure was carried out under general anaesthesia with the patient placed in a lateral decubitus position. A $20-\mathrm{cm}$ longitudinal or curved incision centred on the acromion was made and skin flaps raised and the trapezius and deltoid muscles exposed. The deltoid muscle was mobilised from the distal third of clavicle, acromion, and the lateral third of the spine of the scapula. The insertion of the trapezius at the lateral end of clavicle, acromion, and spine of scapula identified. An oblique osteotomy of the base of acromion and clavicle was done and the trapezius muscle along with the acromion mobilised medially as far as possible by blunt dissection preserving the neurovascular bundle medially. Proximal humerus exposed by longitudinally splitting the deltoid muscle and the bone surface prepared by removal of periosteum and roughening of the cortex. With the arm in $90^{\circ}$ abduction and maximal external rotation the acromion was transferred to humerus below the greater tuberosity and fixed with two or three $4.5 \mathrm{~mm}$ cancellous screws. The deltoid muscle that was freed partially earlier was sutured on top of the trapezius muscle under maximum tension as far medially as possible. The wound was closed over a suction drain. The arm was immobilised at $90^{\circ}$ abduction and maximal external rotation by a Plaster of Paris slab during the initial postoperative period and later using a custom made aluminium splint for 6 weeks. After 6 weeks a radiograph was taken to check the transferred acromion and then progressive adduction of the shoulder was done over one week followed by isometric contraction training of the trapezius in co-contraction with rhomboids.

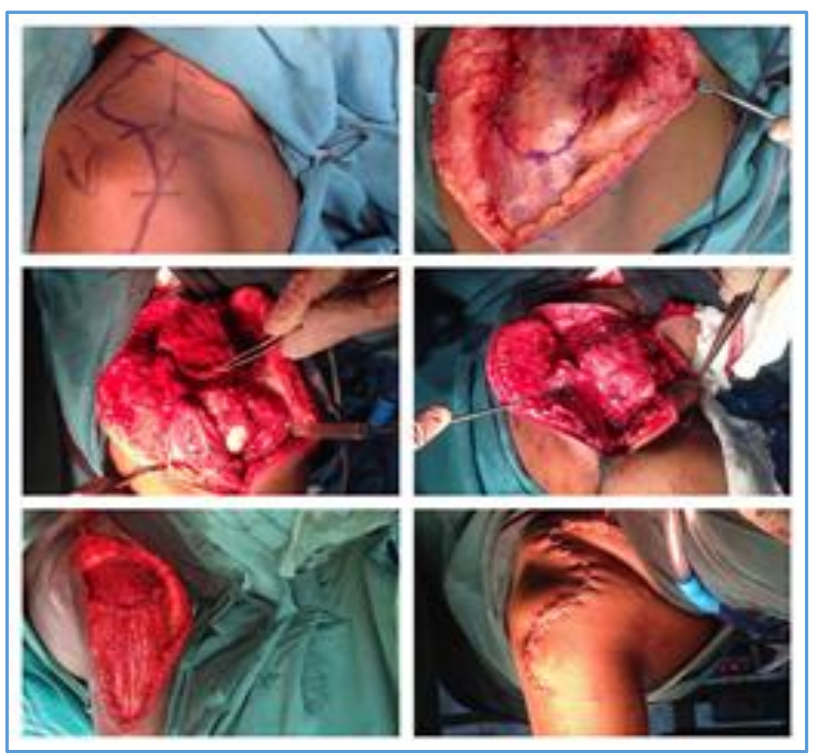

Figure 1. Operative Procedure

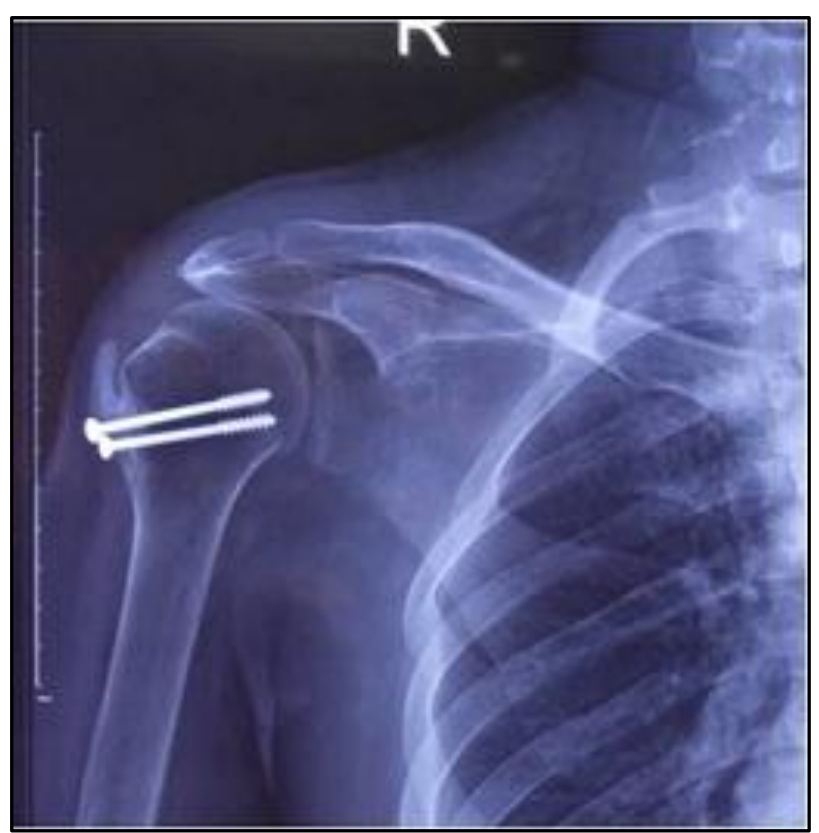

Figure 2. Post-operative X-ray Showing Transferred Trapezius with Acromion 


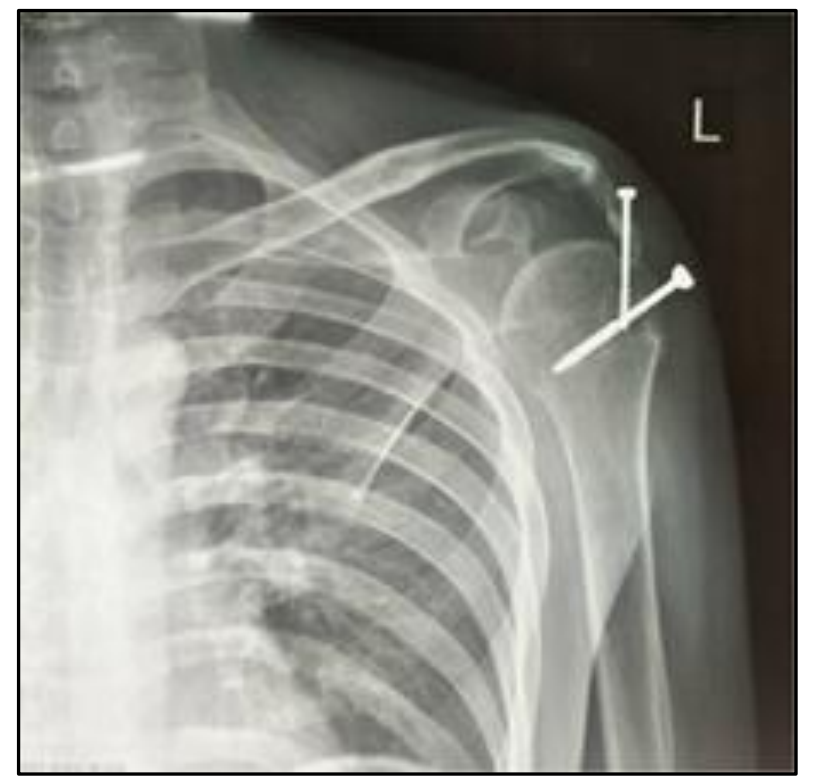

Figure 3. X-Ray Showing Loosening of Screw

\section{RESULTS}

The shoulder function was improved in 35 of the 42 patients. The average gain in shoulder abduction was $40.68^{\circ}$ (Range $0^{\circ}$ to $90^{\circ}$ ) and the average gain in shoulder forward flexion was $35.36^{\circ}$ (Range $10^{\circ}$ to $75^{\circ}$ ). $92.86 \%$ of the patients had their inferior subluxation of the humerus corrected radiographically. The passive preoperative shoulder mobility was regained fully in all patients after completion of the physiotherapy. One patient developed haematoma during the early postoperative period and the same was evacuated and secondary suturing of the wound done. Three patients had loosening of screws.

\section{DISCUSSION}

The Muscle Acting around the Shoulder Joint can be Organised into Three Groups

1. Prime movers- Deltoid and Pectoralis Major (clavicular head).

2. Steerers- Supraspinatus, Infraspinatus, and Subscapularis.

3. Depressors- Latissimus dorsi, Teres major and minor, and Pectoralis major (pectoral head).

The loss of function at the shoulder joint results in crippling deformity of the upper limb and the limb cannot be used to carry out day-to-day activities even if other joints of the upper limb are functioning well. In such cases, the secondary reconstruction of shoulder function includes shoulder fusion or muscle transfer. Each procedure has its own advantages and disadvantages.

The advantages of shoulder fusion are the greater chance of success and the greater strength and power of the functional force at the shoulder. The disadvantages are a limited range of abduction, ${ }^{4}$ normal mobility of the scapulothoracic joint is a prerequisite and this is an irreversible procedure. Arthrodesis inhibits the passive mobility of the joint, making some useful movement like dressing 5 or putting the hand in the pockets, ${ }^{12}$ back of the head or to the opposite side of the body difficult. Arthrodesis is associated with a high incidence (About one fifth) of complications, such as fractures ${ }^{1,2}$ and pseudoarthrosis. ${ }^{12,4}$
Pain in the shoulder region is common after arthrodesis, 13,3 and many patients are dissatisfied 1,2 and some feel worse than before surgery. ${ }^{13}$

The advantages of muscle transposition are the possibility of a greater range of motion at the shoulder joint, minimal or no interference with the passive range of motion at the shoulder joint. Another advantage of muscle transfer is that the shoulder fusion can be done at a later date if the muscle transfer fails to produce the required results.

When shoulder arthrodesis fails, no other option remains for reconstruction of the shoulder function. In view of cosmetic reason, arthrodesis is not preferred in females as it causes the arm to project out from the side.

Some authors prefer arthrodesis to muscle transfer, 11,14,2,3,15 some authors consider that muscle transfers are better than shoulder arthrodesis. ${ }^{7,8}$ Saha $^{5}$ and Goldner 6 came to the conclusion that shoulder arthrodesis should be regarded as the last resort and muscle transfers as the best option.

Various muscle transfers such as trapezius, pectoralis major and teres major, latissimus dorsi, combined biceps and triceps, gracilis, and combined muscle transfers have been used in the secondary reconstruction of the shoulder. The major problem in traumatic brachial plexus is the availability of fully functional muscle for transfer. The levator scapulae, rhomboids, and trapezius muscles are spared in almost all cases of traumatic brachial plexus injuries. ${ }^{16}$

The lever arm of the transferred trapezius is lesser when compared to other transfers and in spite of this it is better than other muscle transfer because the movement takes place in the plane of the scapula and this provides the stability and mobility. ${ }^{17}$ The trapezius muscle is found to be hypertrophied in most of the patients with paralysis of the deltoid muscle. ${ }^{17}$ Many methods of trapezius to deltoid tendon transfer were published: Mayer (1927),18 Ober (1932),19 Harmon (1950), 7 Bateman (1955) ${ }^{11}$ and Saha (1967). ${ }^{5}$ The surgical technique was initially described by Mayer (1927), 18 who also used a fascia lata plasty to increase the length of the trapezius insertion. Bateman (1955)11 described the transfer with acromion osteotomy and other experiences were later published by several authors (Saha 1967,5 Karev 1986,10 Aziz et al. $1990^{\circ}$ ). To achieve the necessary tension in trapezius transfer, the fixation of the acromial fragment is done as far as distal on the humerus as possible. This will be limited by the degree to which the muscle can be mobilised without injuring the neurovascular bundle medially. Saha ${ }^{5}$ describes suture of the partially freed deltoid muscle on top of the trapezius after fixation of the acromion. By doing this the power of the trapezius is carried over to the area of insertion of deltoid to the humerus by the atrophied fibres of the deltoid muscle and this increases the length of the lever arm. The deltoid muscle also protects the transferred trapezius which is stressed because of the maximum tension.

In our study, the trapezius transfer was done following the technique used by Bateman ${ }^{11}$ and Saha $^{5}$ with the following modification. The skin incision that we have used was longitudinal, as we felt that this will allow an adequate exposure of all the surgical field and it can be extended proximally when a more extensive release of the trapezius is needed.

Some studies have achieved excellent functional results with more than $75^{\circ}$ average shoulder abduction and forward 
flexion, but in large series the average gains in post-operative

range of motion were comparable to our study.

\begin{tabular}{|c|c|c|c|c|c|c|c|c|}
\hline \multirow{2}{*}{ Authors } & \multirow{2}{*}{$\begin{array}{l}\text { Total } \\
\text { Number } \\
\text { of } \\
\text { Patients }\end{array}$} & \multirow{2}{*}{$\begin{array}{c}\text { Duration } \\
\text { of Follow- } \\
\text { Up } \\
\text { (Months) }\end{array}$} & \multicolumn{2}{|c|}{$\begin{array}{l}\text { Shoulder Abduction } \\
\text { Mean in Degree } \\
\text { (Range) }\end{array}$} & \multicolumn{2}{|c|}{$\begin{array}{c}\text { Shoulder Forward } \\
\text { Flexion } \\
\text { Mean in Degree (Range) }\end{array}$} & \multicolumn{2}{|c|}{$\begin{array}{c}\text { Inferior } \\
\text { Subluxation (\%) }\end{array}$} \\
\hline & & & $\begin{array}{c}\text { Pre- } \\
\text { operative }\end{array}$ & $\begin{array}{c}\text { Post- } \\
\text { operative }\end{array}$ & $\begin{array}{c}\text { Pre- } \\
\text { operative }\end{array}$ & $\begin{array}{c}\text { Post- } \\
\text { operative }\end{array}$ & $\begin{array}{c}\text { Pre- } \\
\text { operative }\end{array}$ & $\begin{array}{c}\text { Post- } \\
\text { operative }\end{array}$ \\
\hline Aziz et $\mathrm{al}^{9}$ & 27 & 15 & $\begin{array}{c}4 \\
(0 \text { to } 30)\end{array}$ & $\begin{array}{c}45 \\
\text { (20 to } 120)\end{array}$ & $\begin{array}{c}4 \\
(0 \text { to } 50)\end{array}$ & $\begin{array}{c}35 \\
(0 \text { to } 20)\end{array}$ & 100 & 0 \\
\hline Karev $^{10}$ & 1 & - & - & 180 & - & 180 & - & - \\
\hline Kotwal et $\mathrm{al}^{20}$ & 26 & 26 & - & 46 & - & - & - & - \\
\hline Mayer ${ }^{18}$ & 6 & - & - & $\begin{array}{c}\text { 2: poor } \\
\text { 4: Gratifying }\end{array}$ & - & - & - & - \\
\hline Mir-Bullo et al 21 & 6 & 19 & $\begin{array}{c}13 \\
(0 \text { to } 30)\end{array}$ & $\begin{array}{c}76 \\
\text { (50 to } 100)\end{array}$ & $\begin{array}{c}18 \\
(0 \text { to } 40)\end{array}$ & $\begin{array}{c}78 \\
(45 \text { to } 110)\end{array}$ & - & - \\
\hline Rühmann et al22 & 31 & 24 & $\begin{array}{c}7 \\
(0 \text { to } 45)\end{array}$ & $\begin{array}{c}39 \\
(25 \text { to } 80)\end{array}$ & $\begin{array}{c}20 \\
(0 \text { to } 85)\end{array}$ & $\begin{array}{c}44 \\
\text { (20 to } 90)\end{array}$ & 97 & 16 \\
\hline Singh et al 23 & 8 & 15.3 & $\begin{array}{c}13 \\
(0 \text { to } 30)\end{array}$ & $\begin{array}{c}116 \\
\text { (45 to } 180)\end{array}$ & $\begin{array}{c}24 \\
\text { (15 to } 30)\end{array}$ & $\begin{array}{c}107 \\
\text { (90 to } 180)\end{array}$ & - & - \\
\hline Yadav 24 & 24 & $12-36$ & - & $\begin{array}{c}\text { 16: MRC } 3 \text { to } \\
4 \\
\text { 8: } M R C<3\end{array}$ & - & - & - & - \\
\hline Our Study & 42 & 14 & $\begin{array}{c}10 \\
(0 \text { to } 20)\end{array}$ & $\begin{array}{c}40 \\
(0 \text { to } 90)\end{array}$ & $\begin{array}{c}15 \\
(0 \text { to } 30)\end{array}$ & $\begin{array}{c}35 \\
(10 \text { to } 75)\end{array}$ & 100 & 92.86 \\
\hline
\end{tabular}

The major drawback of this procedure was the postoperative immobilisation for 6 weeks in an uncomfortable position. The immobilisation in $90^{\circ}$ shoulder abduction interfered with the daily activity of the patient.

An additional advantage of the trapezius transfer procedure is the correction of the inferior subluxation of the shoulder joint. The weight of the flail upper limb creates a constant pull on the shoulder joint and stretches the capsule of the shoulder joint. This leads to constant pain in the region of the shoulder joint. In our study, the failure of correction of inferior subluxation was noted in $7.14 \%$ of the patients. The reason for the failure is loosening of the screw with persistent inferior subluxation of the humerus.

Osteoporosis due to inactivity is usually found in the structure of the bones of the patients with longstanding brachial plexus palsy. This can lead to difficulty in the fixing of the acromion fragment to the proximal humerus and also loosening of the screw during the post-operative period. We are of the view that the problem of loosening of the screw could be minimised by using a fully threaded cancellous screw that is fixed after placing a washer.

The procedure is relatively simple compared to arthrodesis. The only contraindication is lack of passive range of motion at the shoulder joint. The passive range of motion in the shoulder joint should be adequate for the transfer to work. If adequate passive range of motion cannot be obtained, then trapezius transfer should not be done for improvement of the shoulder function.

\section{CONCLUSION}

The transfer of trapezius is a simple procedure which can restore the abduction and forward flexion of the shoulder in a majority of the patients with traumatic brachial plexus injury.

\section{REFERENCES}

[1] Chammas M, Meyer ZR, Allieu Y. Arthrodesis of the shoulder for post-traumatic palsy of the brachial plexus. Analysis of a series of 18 cases. Rev Chir Orthop Reparatrice Appar Mot 1996;82(5):386-95.

[2] Cofield RH, Briggs BT. Glenohumeral arthrodesis. Operative and long-term functional results. J Bone Joint Surg Am 1979;61(5):668-77.

[3] Richards RR, Waddell JP, Hudson AR. Shoulder arthrodesis for the treatment of brachial plexus palsy. Clinical orthopaedics and related research 1985;198:250-8.

[4] Vastamäki M. Shoulder arthrodesis for paralysis and arthrosis. Acta orthopaedica Scandinavica 1987;58(5):549-53.

[5] Saha AK. Surgery of the paralysed and flail shoulder. Acta Orthopaedica Scandinavica 1967;38(Suppl 97):390.

[6] Goldner JL. Strengthening of the partially paralyzed shoulder girdle by multiple muscle-tendon transfers. Hand clinics 1988;4(2):323-36.

[7] Harmon PH. Surgical reconstruction of the paralytic shoulder by multiple muscle transplantations. JBJS 1950;32(3):583-95. 
[8] Makin M. Early arthrodesis for a flail shoulder in young children. J Bone Joint Surg Am 1977;59(3): 317-21.

[9] Aziz W, Singer RM, Wolff TW. Transfer of the trapezius for flail shoulder after brachial plexus injury. Bone \& Joint Journal 1990;72(4):701-4.

[10] Karev A. Trapezius transfer for paralysis of the deltoid. The Journal of Hand Surgery: British \& European Volume 1986;11(1):81-3.

[11] Bateman JE. The shoulder and its environs. St. Louis: CV Mosby 1955.

[12] Ducloyer P, Nizard R, Sedel L, et al. Shoulder arthrodesis in brachial-plexus injuries-a 23 cases report. Revue de chirurgie orthopedique et reparatrice de l appareil moteur 1991;77(6):396-405.

[13] Neer CS, Hawkins RJ. Functional-analysis of shoulder fusions. Journal of bone and joint surgery-British 1977;59(4):508.

[14] Beltran JE, Trilla JC, Barjau R. A simplified compression arthrodesis of the shoulder. J Bone Joint Surg Am 1975;57(4):538-41.

[15] Rowe CR. Re-evaluation of the position of the arm in arthrodesis of the shoulder in the adult. J Bone Joint Surg Am 1974;56(5):913-22.

[16] Narakas AO. Muscle transpositions in the shoulder and upper arm for sequelae of brachial plexus palsy. Clinical neurology and neurosurgery 1993;95:89-91.
[17] Comtet JJ, Herzberg G, Naasan IA. Biomechanical basis of transfers for shoulder paralysis. Hand clinics 1989;5(1):1-4.

[18] Mayer L. Transplantation of the trapezius for paralysis of the abductors of the arm. J Bone Joint Surg Am 1927;9(3):412-20.

[19] Ober FR. An operation to relieve paralysis of the deltoid muscle. Journal of the American Medical Association 1932;99(26):2182.

[20] Kotwal PP, Mittal R, Malhotra R. Trapezius transfer for deltoid paralysis. J Bone Joint Surg Br 1998;80(1): 114-6.

[21] Mir-Bullo X, Hinarejos P, Mir-Batlle P, et al. Trapezius transfer for shoulder paralysis: 6 patients with brachial plexus injuries followed for 1 year. Acta Orthopaedica Scandinavica 1998;69(1):69-72.

[22] Rühmann O, Wirth CJ, Gossé F, et al. Trapezius transfer after brachial plexus palsy. The Journal of bone and joint surgery 1998;80(1):109.

[23] Singh AK, Karki D. Modified trapezius transfer technique for restoration of shoulder abduction in brachial plexus injury. Indian Journal of Plastic Surgery 2007;40(1):39-46.

[24] Yadav SS. Muscle transfer for shoulder abduction paralysis of the shoulder in poliomyelitis. Clinical orthopaedics and related research 1978;135:121-4 